\title{
ARTIGO
}

dOI https://doi.org/10.22481/praxis.v15i32.5057

\section{A FORMAÇÃO CONTINUADA E OS ESPAÇOS-TEMPO NA EDUCAÇÃO INFANTIL: ENSAIOS E EXPERIMENTAÇÕES}

\author{
CONTINUED TRAINING AND TIME SPACES IN CHILDREN EDUCATION: TESTS \\ AND EXPERIMENTS
}

\section{LA FORMACIÓN CONTINUADA Y LOS ESPACIOS-TIEMPO EN LA EDUCACIÓN INFANTIL: ENSAYOS Y EXPERIMENTACIONES}

\author{
Renata Sieiro Fernandes \\ Centro Universitário Salesiano de São Paulo - Brasil
}

\author{
Andrea Desidério da Silva \\ Universidade Estadual de Campinas - Brasil
}

\begin{abstract}
Resumo: Na Educação Infantil o tema do espaço-tempo é uma problemática de enfrentamento, pois a partir dela se estruturam e organizam as práticas educativas infantis. Este artigo apresenta e analisa o curso de formação nesta temática, para professores, agentes, monitores e especialistas da Educação Infantil da Rede pública de Campinas-SP. Metodologicamente, o curso se estruturou sob a forma de discussão de conceitos, bases teóricas, vídeos, textos para leitura e exercícios corporais em grupo. Os princípios norteadores foram o autoconhecimento e a experiência por meio de reflexões e de exercícios corporais. O referencial teórico baseia-se em conceitos derivados da Filosofia/Psicanálise, Sociologia e Pedagogia, a partir de Larrosa, Norbert Elias, Maturana, Freinet entre outros. Considerase que, para uma ação docente refletida e adequada, é preciso tomar referências teóricas e práticas de outros lugares e fazer novas perguntas para deslocar-se e re-conhecer-se, assumindo a formação continuada por meio de ensaios e experimentações e não por indicações prescritivas que direcionam o fazer educativo.
\end{abstract}

Palavras-chave: Educação Infantil; Espaço-tempo; Formação continuada.

\begin{abstract}
The theme of space-time in Infant Education is a problematic focused, because from it are structured and organized educational practices with children. This article presents and analyzes the training course in this subject, for teachers, agents, monitors and specialists of the municipal school of early childhood education, Campinas, SP. Methodologically, the course was structured in the form of discussion of concepts, theoretical bases, videos, texts for reading and group exercises. The guiding principles were self-knowledge and experience through reflections and body exercises. The theoretical reference is based on concepts derived from Philosophy / Psychoanalysis, Sociology and Pedagogy, from Larrosa, Norbert Elias, Maturana, Freinet and others. It is considered that, for a reflected and adequate teaching action, it is necessary to take theoretical and practical references from other places
\end{abstract}


and ask new questions to move and get to know one another, taking on the continuous formation through tests and experiments and not for Prescriptive directions that guide the educational achievement.

Key-words: Child education; Space time; Continuing education.

Resumen: En la Educación Infantil el tema del espacio-tiempo es una problemática de enfrentamiento, pues a partir de ella se estructuran y organizan las prácticas educativas infantiles. Este artículo presenta y analiza el curso de formación en esta temática, para profesores, agentes, monitores y especialistas de Educación Infantil de la Red pública de Campinas-SP. Metodológicamente, el curso se estructuró bajo la forma de discusión de conceptos, bases teóricas, videos, textos para lectura y ejercicios corporales en grupo. Los principios orientadores fueron el autoconocimiento y la experiencia por medio de reflexiones y de ejercicios corporales. El referencial teórico se basa en conceptos derivados de la Filosofía / Psicoanálisis, Sociología y Pedagogía, a partir de Larrosa, Norbert Elias, Maturana, Freinet entre otros. Se considera que, para una acción docente reflejada y adecuada, es necesario tomar referencias teóricas y prácticas de otros lugares y hacer nuevas preguntas para desplazarse y re-conocerse, asumiendo la formación continuada por medio de ensayos y experimentaciones y no por indicaciones prescriptivas que orientan el hacer educativo.

Palabras clave: Educación infantil; Espacio-tiempo; Formación continua.

\section{Introdução}

Não apenas quem aprende, mas também quem ensina, precisa saber que se procuramos uma coisa diferente também precisa ser diferente o modo de procurá-la. (RUSSO, 2008, p. 162)

Este artigo trata-se de um ensaio em que aspectos decorrentes de um curso de formação realizado são problematizados, especialmente aqueles que circunscrevem a dimensão conceitual espaço e tempo.

A epígrafe acima serve de mote para se pensar e pôr em prática um curso de formação continuada para professores e monitores, em início de carreira ou em vias de aposentadoria, que atuam na área da Educação, especialmente, da Educação Infantil, buscando inspiração na experiência e na busca do novo em detrimento do que é restritivo e prescritivo nas propostas comumentemente presentes no ambiente escolar. Os cursos de formação são momentos e modos de se ajudar a construir e refletir sobre a prática docente. São oportunidades para se repensarem e reencaminharem saberes e fazeres docentes pessoais e de contribuir para a construção da identidade do campo da Educação Infantil em sua busca pela não escolaridade e pela singularidade da educação da infância.

Como diz Rocha (2003, p. 16) sobre a função social das instituições de Educação Infantil, 
Diferenciam-se, escola e creche, essencialmente quanto ao sujeito, que neste último caso é a criança, e não o sujeito- escolar (o aluno). Diferenciam-se ainda quanto à definição de suas funções, pois se o ensino fundamental tem constituído historicamente uma pedagogia escolar que visa aprendizagens específicas; as funções da creche, como já vimos, encontram-se em processo de definição de sua finalidade social e resultam numa pedagogia ainda em constituição.

Portanto, esses marcos diferenciadores do que é a escola, marcada pelo ensino nos níveis fundamentais em diante, servem como referência contrária ao que deve ser a identidade das instituições de Educação Infantil que ainda está em processo.

Para Faria (2007, p. 291) esta deve ser entendida como não escolar ou como vias não formais de educação. Nas palavras da autora: sujeito-escolar

Outras formas de educação das crianças desta faixa etária que não se enquadrarem no sistema formal de educação e ensino do país, assim não se caracterizando como primeira etapa da educação básica, podendo ser governamentais ou não governamentais, farão parte da construção de uma política plural de atenção e educação da criança pequena e assim são chamadas de educação infantil por vias não formais. (...) A educação infantil não é escolar, devendo estar centrada na produção das culturas infantis e não no ensino, nem na antecipação, nem na preparação para a escola obrigatória.

A Lei de Diretrizes e Bases da Educação Nacional (LDBEN) (2005) garante a Educação Infantil liberdade e flexibilidade para construir seu próprio currículo bem como para a organização espaço-tempo dos grupos.

Como parte das discussões sobre a identidade da Educação Infantil o tema do espaçotempo é uma necessidade e uma problemática de enfrentamento, pois a partir dela se estruturam e organizam as práticas educativas infantis. Desta forma, as redes públicas municipais de Educação oferecem cursos que ajudem seus profissionais a tomarem parte ativa na formulação de questões e no encaminhamento de enfrentamentos delas, buscando algo diferente e que melhor traduza o conceito de criança como sujeito de direitos.

A rede pública municipal de Educação de Campinas-SP oferece cursos e possibilita que as escolas organizem suas formações vislumbrando, entre outros, a discussão dos seus documentos oficiais (Parâmetros Curriculares, Diretrizes Curriculares da Educação Básica para a Educação Infantil um Processo Contínuo de Reflexão e Ação, Caderno Curricular Temático Espaços e Tempos na Educação das Crianças) que regulamentam a metodologia e o currículo da Educação Infantil, sendo que uma das temáticas abordadas refere-se ao espaçotempo. 
Tomando-se como ponto de referência o que apresentam os documentos citados acima, o projeto político pedagógico da instituição de Educação contempla o currículo que pensa a formação dos sujeitos e dos grupos sociais e, para tanto, lança mão de didáticas ou processos metodológicos que compõem a pedagogia posta em prática na instituição.

O documento das Diretrizes Curriculares da Educação Básica para a Educação Infantil um Processo Contínuo de Reflexão e Ação (2013) propõe que, democraticamente, esse currículo seja pensado coletivamente elaborado e posto em prática a partir das necessidades e urgências da comunidade escolar e do entorno.

(Re)pensar o currículo é uma ação que envolve avaliar e refletir sobre a prática educativa e buscar ajustes, reformulações ou mudanças nos fundamentos teóricos e nos fazeres prático-metodológicos, que o curso de formação continuada propicia.

Segundo este documento,

Numa gestão democrática, o currículo deve respeitar as necessidades e
interesses dos estudantes e suas famílias. Esse respeito é demonstrado
quando o currículo, na escola, articula as orientações mais gerais de uma
Diretriz como esta, que irá propor a universalização de alguns aspectos da
formação geral das crianças, jovens e adultos de nossa Rede de Ensino, com
as temáticas e os problemas que mobilizam a comunidade em que esta escola
está inserida. Sem o respeito ao aluno, que se manifesta na consideração de
sua cultura e de seus saberes, a escola não pode promover aprendizagem, a
qual não existe sem o envolvimento dos sujeitos na construção ativa de seus
conhecimentos. (DIRETRIZES, 2013, p. 9 e 10)

Faz parte dos objetivos das Diretrizes das Unidades Educacionais da Rede, "desenvolver processos criadores de uma nova vida, uma nova humanidade" (2013, p. 18) e, para tanto, menciona a formação de professores - que promovem a formação de educandos em diversas dimensões. É este o sentido que os cursos de formação continuada pretendem abarcar, tanto em termos de conteúdos metodológicos, como promovendo e instigando questionamentos e reflexões.

Desta forma, de acordo com o que anuncia o documento, o curso de formação se pauta "pela leitura, estudo e pesquisa, contribuindo para que os profissionais apreendam métodos de análise e investigação sobre os problemas que emergem da relação pedagógica com as crianças, jovens e adultos e suas famílias” (p. 64), partindo das práticas já desenvolvidas, problematizando-as para a busca de novos rearranjos no caso de necessidades ou interesses.

Trazer à tona a reflexão sobre a construção e organização dos espaços-tempos nas unidades escolares tem sido premente na rede municipal de Educação de Campinas-SP, nas 
unidades de Educação Infantil, como mostra o documento Caderno Curricular Temático Espaços e Tempos na Educação das Crianças (2014).

Dos objetivos indicados no documento anteriormente mencionado aparece exatamente:

Problematizar a organização do trabalho pedagógico presente no cotidiano das unidades de Educação Infantil, a partir das concepções de educação e infância;

Destacar a importância do planejamento e da organização dos tempos e espaços cotidianos por parte das profissionais e crianças, dialogando com pressupostos teóricos referentes à temática. (CADERNO, 2014, p. 16)

Este artigo apresenta e analisa o curso de formação ${ }^{1}$ ministrado pelas autoras, no ano de 2016, para professores, agentes, monitores e especialistas da Educação Infantil da Rede Municipal de Ensino de Campinas-SP, abordando o tema do espaço-tempo na Educação Infantil a partir de suas especificidades ${ }^{2}$.

Ao reconhecer a construção do conhecimento como não organizado, institucionalmente, sob a forma de lista de conteúdos e objetivos ligados diretamente a eles, bem como uma listagem sequencial, linear, hierárquica, que parte do local para o amplo, a proposta do curso de formação se pautou pela organização por eixos, favorecendo o desenvolvimento das capacidades necessárias à formação dos sujeitos, de tal forma que a ação educativa funcionasse não de forma arbórea, compartimentando os saberes, mas por enredamento ou por rizoma, com atravessamentos de áreas de conhecimento e com ênfase na construção conceitual da realidade por meio do trabalho ativo.

Os documentos que embasam, sustentam e orientam as práticas educativas com crianças pequenas ressaltam aspectos extremamente interessantes que deram inspiração e sustentação para a proposta do curso de formação, como: "movimento", "vida", "inovação", “transgressão" (Caderno, 2014, p. 16), “efemeridade”, “mutabilidade”, “criação” (Caderno, p. 16), "ultrapassar limites" (Caderno, 2014, p. 28) entre outros, sendo muito pouco prescritivos e normativos, dando abertura e flexibilidade para os profissionais e as unidades de educação criarem suas marcas e apostarem em seus projetos e utopias.

\footnotetext{
${ }^{1}$ O curso foi organizado a partir da demanda do Projeto Político Pedagógico da escola em questão, que, na sua singularidade, apresenta uma nova proposta de organização espaço-tempo, o que refletiu em uma necessidade de formação. A ideia do curso e a escolha das formadoras têm como princípio a problematização teórica dessa temática bem como a troca de experiências.

${ }^{2}$ A proposta de curso de formação passa pelo Núcleo de Ação Educativa Descentralizada (NAED), da Secretaria Municipal de Educação e, na sequência, pelo CEFORTEPE, que é destinado à formação dos profissionais da educação, vinculado à Coordenadoria Setorial de Formação. Esses segmentos avaliam se a proposta de curso de formação está de acordo com o Projeto Político Pedagógico da escola.
} 
Desta forma, entendemos a Educação Infantil como espaço de invenção e criação, sendo não escolar ou via não formal (Faria, 2007, p. 291), apostando nos conceitos de experimentação e ensaio; tateio e erro e campo de experiência.

\section{Desenvolvimento}

O curso de formação continuada aconteceu no período de abril a agosto de 2016, uma vez por semana, para professores, agentes, monitores e especialistas da Educação Infantil da Rede Municipal de Ensino de Campinas-SP - totalizando 28 pessoas -, com carga horária de 40h em cada uma das duas turmas.

Os objetivos gerais do curso de formação continuada foram: a) promover pensamentos e reflexões sobre a prática educativa com crianças pequenas problematizando o instituído e o ajustável na tensão com o risco e o surgimento do novo no campo da Educação; b) subsidiar as reflexões teóricas e práticas-metodológicas na construção do trabalho educativo e na organização dos espaços-tempos da infância na instituição que atende crianças pequenas.

Os eixos de discussão se estruturaram sobre os seguintes temas: a experiência como formação de sujeitos; ensaios e experimentações ou tateios e erros; o conceito de projeto como algo que se lança no tempo e no espaço; mapas, labirintos e derivas - os espaços como saberes geográficos; chronos, kairós e aión - os tempos como saberes históricos; o lúdico, as artes e a cultura como fundamentos da Educação da infância; os registros da prática educativa como dispositivos de reflexividade; o portfólio como registro de memória e de história.

Metodologicamente, o curso se organizou sob a forma de apresentação de conceitos, discussão teórica a partir de vídeos e textos para leitura e exercícios corporais em grupo. Dois pilares embasaram a metodologia: a) que todo conhecimento produzido fosse, primeiro, autoconhecimento, ou seja, antes de falarmos de algo exterior, para o qual muitas vezes já se tem um discurso feito, tratar de pensar como os assuntos ressoam internamente, para então, serem buscadas tentativas de localizá-lo fora, em suas repercussões; e b) passar pela experiência sensorial e corporal em exercícios conjuntos para poder criar bases sensíveis e palpáveis para o surgimento do pensamento reflexivo.

O primeiro pilar baseia-se nas ideias de Naranjo (2015) para quem a educação deve passar a ser para o desenvolvimento humano, ou seja, para o autoconhecimento e o cuidado de si. Para ele, 
Até aqui, temos vivido uma longa história de nobres propostas e revoluções encarniçadas pela mudança social que descuidavam da mudança individual e parece que já é hora que entendamos que, se queremos uma sociedade diferente, necessitamos de seres humanos mais completos: não se pode construir algo desta natureza sem os elementos apropriados. (NARANJO, 2015, p. 121)

A preocupação em desenvolver apenas alguns aspectos do cérebro e o fundamento no conhecimento científico e racional, em detrimento de outros (como o afetivo, o instintivo, o artístico, o filosófico, o mitológico), adoece o sujeito e faz com a que a instituição educativa entre em crise permanente e esta é a oportunidade para a mudança. Ele propõe no lugar do ensino (que implica em pensar métodos para se ensinar a aprender) a educação (que implica em aprendizagem a partir do interesse).

E essa educação tem que passar pelo autoconhecimento. Nas palavras do autor,

[...] a proposta de nos encaminharmos para uma educação verdadeiramente mais relevante para a vida teria que privilegiar o autoconhecimento, o que significaria, junto ao propósito de uma educação para uma convivência feliz, uma reeducação importante dos educadores. (NARANJO, 2015, p. 130)

Embora as apostas dele sejam no aspecto terapêutico e meditativo, a inspiração para nós foi o foco no conhecer a si para poder pensar na ação educativa, em um alinhamento entre o que se sente, o que se pensa, o que se diz, o que se faz.

Para ele, o autoconhecimento passa pela rememoração de experiências passadas $^{3} \mathrm{e}$, também, pelo movimento antes de se tornar pensamento, portanto, integrar o corpo em suas muitas dimensões é a condição para a humanização. Diz ele que, "a propósito, atualmente está provado que a inibição do impulso lúdico causa um considerável dano cerebral, pois existem sinapses que são especificamente estimuladas pelo jogo e depois se perdem” (Naranjo, 2015, p. 123).

Um desses dois apoios, entre outros que ele valoriza, é reiterado por Kenski (s/d), ou seja, a importância na recuperação da memória para a prática docente, percebendo de que modo as experiências passadas influenciam seu trabalho, orientando atos e escolhas. Sendo assim, um rol de perguntas foi lançado no curso de formação, que provocavam lembranças sobre a infância que os eles/elas tiveram e as relações com o espaço-tempo, como: qual a sua lembrança mais distante? Como eram esses lugares? Onde você brincava?

\footnotetext{
${ }^{3}$ Pela tomada de contato com a própria experiência no aqui e agora; tomada de contato, através da recordação, com a experiência passada; a compreensão da experiência do momento no contexto da experiência total (para além do que se sente e do que se pensa, incluindo os insights e a personalidade); a clarificação da compreensão através de formulações teóricas ou mapas de referência.
} 
As perguntas foram apresentadas gradualmente e cada um dos participantes, ao seu tempo, foi construindo caminhos de acesso à história vivida, valendo-se do olhar e da escuta atual para ressignificar o tempo passado e projetar o tempo futuro. E os relatos de cada um sobre a vida infantil alimentavam as memórias dos demais.

As lembranças ressignificadas na contemporaneidade apontaram, especialmente, para duas características: a liberdade e a ausência quase que total de adultos nos momentos de brincadeiras que, ainda que pudesse não ter ocorrido da forma lembrada, faz parte do modo de se imaginar a infância nos jogos de "faz de conta", na montagem das cabanas, nos esconderijos que permitiam aventuras e riscos.

Essas lembranças tomaram assento em lugares que trouxeram à tona sentimentos, sensações e emoções díspares, como: medo, alegria, tristeza, vergonha, amor, força, ousadia, saudade, reveladas em trechos de depoimentos como: "lembrei o cheiro da infância", "vivia de ponta cabeça", "eu tinha muito tempo, hoje o tempo voa", "meu corpo foi muito tolhido", “isso é coisa de menino", "eu cataloguei toda a biblioteca do meu avô, ele era poeta", "assisti muita televisão", "só lembrei das coisas boas, as ruins eu não quis escrever", “eu não ganhava presente nem em aniversário", "as mães nem sabiam aonde a gente estava", "a gente criou maneiras de invadir o asilo", "lembro do grilhão dos escravos".

Os lugares evocados haviam sido visitados diariamente ou nas férias escolares, como: quintais, ruas, sítios, porões, muros, locais abandonados, casas de avó, cama dos pais, árvores, águas e constituíram marcas que ajudam a compor o sujeito de hoje, o/a professora/professor, o/a monitor/monitora.

A ideia contida na provocação das memórias é que os professores/as monitores/as buscassem no tempo da infância, ou com a criança que mora em cada um, para que pudessem tentar identificar as repercussões disso para a prática educativa. E, ainda, que pudessem elencar possibilidades impensadas de trazer as vivências em espaços outros que não os escolares como referências para o espaço da instituição de Educação Infantil.

Outras lembranças evocadas referiram-se à escola e, neste caso, contrapondo-se as respostas anteriores, as imagens que construíram foi a de um lugar não atraente, de aprisionamento do corpo no tempo cronológico e no espaço das carteiras, da normatização e disciplina das filas, das brincadeiras dirigidas, e, em grande parte, fixadas nas regras.

Ainda que se sobressaíssem aspectos negativos nos depoimentos, como: "eu era meio invisível na escola," “a escola era pra oprimir", também revelaram aspectos positivos vivenciados de forma dirigida ou espontânea e as percepções sensoriais do coletivo, como: 
"eu tinha aula de alinhavo na escola", "a professora levava os alunos para uma sala cheia de esqueletos", "a escola tinha cheiro de 'CICA' (Companhia Industrial de Conservas Alimentícias) e eu seguia formigas gigantes", "todo mundo estudava junto, rico, pobre".

Os depoimentos mostraram, ainda, que vínculos afetivos foram estabelecidos com as pessoas mais velhas e os pares, como colegas de turma ou não e professoras/professores, contribuindo, também, como marcas que ajudam a compor o sujeito pessoal e profissional de hoje.

Kenski (s/d, p. 103) lança mão de outras perguntas para provocar recuperação e reflexão sobre si: o que essas experiências significaram em suas vidas? Como se sentiam na época em que viveram essas experiências? Que influências esses momentos tiveram em suas escolhas pessoais e profissionais?

A autora afirma que pesquisas confirmam teoricamente os fatos que

[...] revelam que os professores criam formas personalizadas de atuar em sala de aula, não apenas baseadas no conhecimento do conteúdo da disciplina e da metodologia de ensino específica, mas também de acordo com as vivências que tiveram e que são recuperadas com a ajuda da situação de ensino em que se encontram. (KENSKI, s/d, p. 104)

Valer-se de perguntas que não se relacionam com o fazer educativo serve como estímulo a se distanciar de discursos já construídos sobre a criança, a infância e o espaço educativo em que trabalham. A verbalização e a socialização das memórias ajudam a buscar convergências, divergências e complementaridades entre as narrativas e, a partir delas, buscar elementos que sustentem ou que reformulem a prática educativa diferenciada e que permitam identificar problemas e encaminhar tentativas de soluções.

O outro apoio do curso de formação continuada é o do exercício corporal pautado, primeiro, no conceito do corpo soma, como é entendido pela educação somática e se dá por meio da sugestão de diferentes propostas coletivas nas quais o corpo entra em movimento com a intenção de possibilitar experiências.

O soma, para Hanna (1972, p. 28), um dos pesquisadores pioneiros nesta área,

[...] não quer dizer "corpo"; significa eu, o ser corporal. [...] O soma é vivo; ele está sempre se contraindo e distendendo-se, acomodando-se e assimilando, recebendo energia e expelindo energia. Soma é a pulsação, fluência, síntese e relaxamento - alternando com o medo e a raiva, a fonte e a sensualidade.

Uma teia de pensamentos, conceitos e práticas forma-se a partir desse pensamento de soma, buscando espaços e tempos propícios para experiências pessoais e coletivas que afetem 
cada um/uma dos/as professores/as e monitores/as e que reverberem no trabalho educativo com a criança pequena.

A outra fonte de inspiração foram duas metodologias de trabalho corporal com crianças $^{4}$, a do Grupo Ginástico UNICAMP (GGU), que pesquisa a Ginástica para Todos ${ }^{5}$, e suas criações coreográficas, focando no encontro entre a formação humana e a capacitação, baseada em Maturana (1997). Nestas criações gímnicas a criatividade se dá por meio da exploração de materiais diversos e a apresentação democrática das descobertas corporais. Assim, cada um contribui com a sua possibilidade corporal para a criação do produto final.

A outra metodologia de trabalho corporal foi a dos 3 momentos, defendida por Velardi (1997) que, baseada em Vigotsky, propõe momentos livres de exploração individual ou coletiva para a prática da ginástica e direcionamentos de movimentos e resolução de problemas corporais ${ }^{6}$.

No caso do curso de formação, as propostas de trabalho corporal longitudinais priorizaram provocar e promover a observação, a escuta, o deslocamento da experiência de mover-se sozinho ou em grupo, de entrar em contato consigo e de se relacionar, criando os próprios caminhos, aquecendo-se e os registros gráficos visuais e orais como forma de socialização.

O excesso de ansiedade, o medo de errar, de ficar em silêncio, de suspender, momentaneamente o pensamento, mostraram-se presentes em alguns momentos e em alguns/umas professores/as e monitores/as. A insegurança com o desconhecido, a busca pelo desenho correto, o medo do erro, pode estar diretamente ligada a necessidade do controle, assim como a expressão: "eu não sei desenhar", pode indicar a adesão a modelos que desvalorizam a singularidade e isso pode se expressar, também, no trabalho educativo com as crianças pequenas.

Com o decorrer dos encontros as novas relações foram se construindo e as relações anteriores permanecendo e consolidando. Este foi outro aspecto que chamou a atenção, pois, embora a permanência nos grupos habituais mostre afinidades a serem preservadas, também indica baixa flexibilidade e abertura para o novo, o diferente, reafirmando seguranças e espaços e tempos instituídos.

\footnotetext{
${ }^{4}$ Criadas e desenvolvidas na Faculdade de Educação Física-UNICAMP, na década de 1990, que permanecem até o presente momento em processo de pesquisa, tendo muitos resultados publicados de diferentes maneiras artigos, dissertações, teses, cenas, coreografias, resumos, palestras, aulas.

${ }^{5}$ Demais informações podem ser obtidas no site do grupo: http://www.ggu.com.br/ggu-apresentacao.

${ }^{6}$ As propostas de artes visuais e dança, do grupo Segni Mossi, da artista plástica Anne Marie Holm, das escolas montessorianas, assim como registros da Reggio Emilia também são parte desse soma.
} 
Essas posturas tendem a se refletir nos fazeres da Educação infantil e é preciso, portanto, rever-se e escutar-se, constantemente. As propostas corporais foram, gradualmente, oferecendo a possibilidade da expressão pessoal, do improviso, do novo, abrindo espaço nos corpos para descobertas, potências e afetos.

A intenção de criar campo de experiência na formação continuada dos participantes para que, assim, pudessem compreender o que se pode propor na Educação Infantil, toma como referência Larrosa (2015) e como ele entende o conceito - ou a palavra, como o autor prefere -, no sentido que "a experiência é a que forma, a que nos faz como somos, a que transforma o que somos e o que converte em outra coisa" (p. 48) por meio de seu "caráter selvagem, autotélico e não regulado" (p. 14).

Neste sentido, também as ministradoras do curso somos afetadas, de modo a nos colocarmos "mais além do conhecido, mais além do seguro e do garantido" (Larrosa, 2015, p. 10), pois que estamos expostas ao que surge e abertas para lidar com as manifestações, os repertórios, as surpresas, na tentativa de aproveitar o que acontece e surge e incorporar como material de conhecimento, pensamento e aprendizagem.

Aceitar o campo da experiência é abrir lugar para a experimentação, diferentemente do experimento. A experimentação fundamenta-se na ideia de tateio/tentativa e erro. Freinet (1969) compreendia que a aprendizagem se dá pelo tateio experimental que mescla repertório anterior e improvisação. Quando o sujeito faz um experimento e dá certo, a tendência é que mantenha a ação e a postura e siga em frente. Freinet parte da experiência sem temor do erro e, errando, faz dele sua aprendizagem. É ensaio, portanto, é aprender fazendo.

A criança quando brinca e o artista quando trabalha usam da imaginação para a criação e fazem uso de tateio experimental. Os ateliês de artista e os locais onde as crianças brincam por escolha própria se assemelham no uso que fazem do que dispõem, partindo do caos inicial para estabelecer relações rizomáticas e atribuição de sentidos de modo a compor algo, a dar visibilidade a algo que acontece dentro e fora, no manuseio, na experimentação, produzindo processos e produtos que dizem de suas formas de entender e interpretar o mundo.

Os gabinetes de curiosidade e os laboratórios de ciências naturais, por partirem de outra referência de conhecimento, organizam seus materiais de forma taxionômica, arbórea, de modo a garantir um ponto de referência de onde tudo o mais pode derivar e procuram se apresentar aos visitantes de modo a evitar enganos e equívocos. De qualquer forma, em ambos ainda aparece o exercício do ensaio e do erro, embora o primeiro foque a 
experimentação (cuja base de conhecimento é a arte) e o segundo foque o experimento (cuja base de conhecimento é a ciência).

Ambos os conhecimentos estão presentes nos espaços-tempos educativos e a Educação Infantil tem privilegiado as linguagens artísticas como modos de aprendizagem na relação com a ciência como modo de ensino de informações. De qualquer modo, as relações estabelecidas com o tempo e o espaço podem se aproximar ou variar em termos de percepção e marcação e orientação e desorientação.

Enquanto o tempo de chronos quantifica (porque é linear, sequencial), o de kairós qualifica e o de aión "atemporiza". Vivemos nos 3 tempos e a possibilidade de qualificar o tempo cronológico se dá pela criação, pela entrega e mergulho no presente (aión) e pela captura da oportunidade (kairós). A criança pequena vivencia aión e aproveita de kairós, enquanto que o espaço-tempo institucional de trabalho para o professor se organiza e se estrutura por chronos. Se a Educação Infantil deve partir e focar na criança, como fazer para se religar a outros tempos? Talvez, pela abertura ao novo, que foge ao conhecido e instituído e pela criação, que acontece pela imaginação e invenção.

A noção de tempo é algo construído socialmente, segundo Elias (1988), que difere no modo de entender dos objetivistas, para quem o tempo é algo dado a priori, ou seja, independentemente de os sujeitos existirem, aquele existe na natureza, e que difere dos subjetivistas, para quem o tempo existe nos sujeitos, em sua consciência, ou seja, se não existirem os homens e as mulheres, não existe o tempo. Para Elias, o tempo é pura especulação e é inconclusivo.

O tempo é social e foi construído pelos grupos sociais como a função de ordenação e regulação, seguido de convenção para uso comum, logo, precisa ser aprendido. E o aspecto primordial da compreensão e conceituação do tempo, neste sentido, é a experiência, ou seja, como se experiencia esse "fenômeno", e isto se dará de modos diversos. Como tempo e espaço estão unidos, não é possível sentir e pensar em um sem o outro.

Em um exercício proposto no curso de formação, a sensação provocada pela audição de duas músicas com, praticamente, a mesma duração, porém, com estilos diferentes, variou para os/as professores/as e monitores/as quando expostos a elas. Para a maioria deles/as, a sensação de distensão temporal ou duração, bem como de "respiro", que indica qualidade na apreciação, aconteceu na apresentação da música “Gymnopédie n 1", de Erik Satie ${ }^{7}$. O oposto

\footnotetext{
${ }^{7}$ A música de Erik Satie, compositor e pianista francês se caracteriza por ser minimalista, não se impondo sobre o ambiente e incorporando silêncios. O título Gymnopédie é tido como derivado do antigo
} 
se deu com a apresentação da música "Rise Above", da banda punk Black Flag ${ }^{8}$, que causou incômodo, aflição, desespero. Apesar de todos/as se disporem a ouvir até o final as músicas, era evidente que o aproveitamento da escuta era melhor no primeiro caso em comparação ao segundo caso, seguida de gestos e manifestações corporais como tampar os ouvidos ou rostos crispados e recolhimento.

Embora todos/as permanecessem em sala, o desejo, no segundo caso, era de abandono do espaço pelo tom agressivo da música e que parecia não terminar. No primeiro caso, a agradabilidade proporcionada pela escuta fazia com que desejassem permanecer e diziam que a música parecia que não acabava (a despeito dos gostos particulares de cada um/a para os estilos musicais).

No dizer deles/as apontavam oposições do tipo aceleração-vagarosidade, caos-cosmo, irritabilidade-tranquilidade, invasão-sutileza, dispersão-reflexividade, poder-paixão, tensãorelaxamento. No caso da primeira música, os sujeitos eram transportados para dentro de si, em postura de introspecção e no caso da segunda música, eram lançados para fora de si, em situação de fuga e escape.

A sensação de cheio ou de enchimento aparece em dois sentidos. No caso da primeira música, pelo preenchimento que o sujeito faz nos intervalos silenciosos e nas notas longas, projetando-se ali com contemplação e inspiração. No caso da segunda música, pelo aspecto excessivo de informação, alimentado, inclusive, pela voz, não havendo lugar para o sujeito se colocar, é dispersiva.

A sensação de vazio aparece no caso da primeira música, permitindo ao sujeito vaguear, libertando o pensamento. No caso da segunda música o vazio só se dá por afastamento ou recusa a ela.

As sensações diferenciadas, para os/as professores/as e monitores/as, se davam em razão das estruturas harmônicas ou desarmônicas, da quantidade maior ou menor de notas em um dado intervalo e pela presença maior ou menor de silêncio ou de ruído. O silêncio indicando o vazio e o ruído indicando o cheio.

Para ambas as situações, ainda, os/as professores/as e monitores/as falaram que o silêncio externo permite ouvir ou procurar construir silêncio interno e o ruído externo se soma

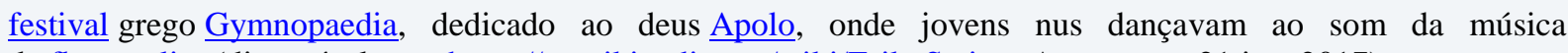
de flauta e lira (disponível em <https://pt.wikipedia.org/wiki/Erik_Satie>. Acesso em: 21 jan. 2017)

${ }^{8}$ A banda punk norte-americana Black Flag se caracteriza por fazer música com muitas notas distorcidas e fortes, com poucos acordes (disponível em < https://pt.wikipedia.org/wiki/Black_Flag >. Acesso em: 21 jan. 2017). 
aos ruídos internos ou então, entram em atrito com os silêncios que já os habitam. Qualificam a experiência positivamente quando há encontro e negativamente quando há choque, tensão.

Em outro exercício, corporal, foi apresentada ao grupo, organizado em duplas, uma sequência de passos ritmados, acompanhando uma música e ao final da execução da sequência, tendo a música continuado, o grupo não sabia como proceder sentindo a suspensão do tempo e o vazio, com o a respiração eclipsada, em movimento labiríntico, para, então, se recomeçar com outra dupla, sem necessidade de alguma determinação interna. Com as trocas de dupla acontecendo continuamente, os ritmos pessoais e coletivos se ajustaram até formarse uma roda e, sem orientação prévia dada por algum comando verbal, chegaram a uma dança circular.

O vazio e o cheio no espaço, para Barbuy (1980), determinam e condicionam o encontro humano, portanto, ele diz da importância do vazio para a expansão e que seu oposto, a saturação do espaço implica a saturação mental. O encontro, para ele, não é proximidade, mas sim, inter-relação pessoal e isso é qualidade.

Ele trata do vazio e do cheio em relação de complementaridade, mas diz da necessidade atual para o esvaziamento, já que vivemos numa excitação dos sentidos, pela busca de informação, pela invasão das mídias e tecnologias.

Nesta relação de complementaridade o autor atribui a cada um dos termos qualificativos diferenciados que implicam em formas diversas de experiência. Ao vazio se relacionam: incerteza, acaso, anarquia, subjetividade, criatividade, dionisíaco, indefinição, incongruência, instabilidade, fantasia, utopia, insegurança, silêncio, intuição, contemplação, meditação, imaginação, sonho e poesia. Ao cheio se relacionam: determinismo, necessidade, totalitarismo, objetividade, aprendizado, apolíneo, planos, previsão, segurança, controle, poder, autoridade, sistematização, método. (Barbuy, 1980, p. 11)

Diz o autor da relação direta da criança com o vazio:

Os criadores mais atrevidos, mais arriscados; os místicos mais profundos têm levado consigo a incerteza e a indefinição como música de fundo, durante toda a sua vida.

O exemplo mais constante e evidente o atualizam as crianças em qualquer parte do mundo; as crianças que ainda têm infância. Essa infância solta e espontânea que somente é possível distante dos programadores e dos que querem formar e conduzir. (BARBUY, 1980, p. 11)

E propõe o direito ao silêncio e ao vazio como forma de encontro consigo e de encontro com o outro em relação. 
Como esvaziar a Educação Infantil para dar lugar a infância e vivenciar o vazio? Esvaziar dentro para poder criar o vazio fora. Neste sentido, outro exercício pelo qual passaram os participantes foi extraído da pedagogia montessoriana e diz respeito ao jogo do silêncio, que ajuda a ter calma e concentração, esvaziamento, entrega e presença. Em dupla, um dos participantes acende uma vela para o outro que está a sua frente e este fecha os olhos e passa a prestar atenção a si e a se desligar dos ruídos externos. Quando transcorrido 1 minuto, o primeiro participante sussurra no ouvido do segundo o seu nome e este "desperta", apagando a vela com um sopro. Depois, os dois trocam de posição para que todos possam passar pela experiência.

A devolutiva dos participantes ao final do exercício variou entre a sensação positiva em relação ao esvaziamento do pensamento e a experimentação de um tempo não cronológico, bem como a dificuldade de entrega e o excesso de pensamento que os recolocava no tempo cronológico.

Para se pensar o espaço e a relação estabelecida com ele de modos diversos, três conceitos extraídos do saber geográfico serviram como suporte para a experiência: o mapa que indica onde estamos, logo, nos orienta na localização presente, mas também, mostra e aponta caminhos para onde se pretende chegar, logo, permite uma relação de planejamento futuro, calculada e segmentada; o labirinto - que indica desorientação, logo, permite o perderse, o que implica em improvisação; a deriva - que indica o vaguear sobre algo conhecido, experimentando caminhos novos e surpresas sobre algo planificado e previsível. Portanto, o mapa permite uma relação com o tempo futuro enquanto o labirinto e a deriva permitem a relação com o tempo presente, sujeito ao que surge e ao que acontece. O mapa indica governabilidade, enquanto que o labirinto e a deriva indicam seu oposto; o mapa é a visão aérea, do alto e de longe, o que permite o controle, o labirinto e a deriva são a visão de proximidade, de perto e de dentro, o que permite "lançar mão" e aproveitar oportunidades, valendo-se de táticas para resolver o que surge naquele momento.

Momentos e situações podem acontecer e serem criados, mas para a experiência artística que se abre para o inusitado, o acaso e para o surgimento do novo, elas se dão na deriva.

A Pedagogia é uma área que lida com o previsível e o planejado muito mais do que com o imprevisto e o improviso, ainda que não se possam prescindir deles, pois eles são a vida em andamento e em movimento. Por isso, para alguns participantes foi aflitivo e até desesperador, causando ansiedade e insegurança, experimentar situações que escapassem ao 
seu controle e a governabilidade, ainda que estivessem na companhia uns dos outros e em um trabalho coletivo.

Isso se dá tanto na prática cotidiana do trabalho educativo quanto nos exercícios propostos no curso, mas foi interessante perceber como se abriram e se entregaram para experimentar o novo da situação e de si. O mesmo vale para as percepções positivas que fizeram no sentido da satisfação com as surpresas e com as combinações possíveis feitas do que estava ao alcance em termos de repertórios materiais, humanos, cognitivos e emocionais.

Nos exercícios corporais propostos, como o do jogo do espelho, do jogo da sombra e do jogo do irmão siamês, sempre em duplas, os desafios foram inseridos na medida em que o jogo se desenvolvia. No jogo do espelho alguém se posicionava de frente para o outro e, após a indicação de um mestre, este tinha que movimentar-se para que seu "espelho" o seguisse imitando a sua imagem de forma contrária. O jogo de sombra seguiu a mesma lógica do jogo anterior, entretanto, neste caso, o mestre ia à frente de alguém e iniciava uma movimentação que precisava ser copiada simetricamente pela "sombra". No jogo do irmão siamês a dupla ficava unida lateralmente.

Para a movimentação, foi sugerida a exploração dos diferentes níveis de altura (baixo, médio e alto) e a não assunção de um mestre-guia, ao que o grupo foi reagindo de forma criativa, havendo deslocamento e movimento do corpo todo, com contatos gestuais e pontuais entre alguns. O jogo finalizava com o desligamento da dupla inicial e união com outra pessoa para gerar novos desafios ou, então, permanecia-se só e experimentava-se um movimento ou gesto diferente, fazia-se pausas observações e escutas sensíveis, identificando maneiras potentes de contribuir, de compor, de cuidar e de (auto)conhecer.

A proposta do curso não foi apresentar ou indicar algum modelo metodológico que pudesse ser desenvolvido na prática educativa com crianças pequenas, mas sim, propor ideias, conceitos e exercícios que pudessem embasar recriações no fazer cotidiano, a partir de criações coletivas de partilhas e socializações. Assim como não indicamos caminhos que se supusessem fossem os melhores em termos metodológicos, tampouco foi defendida a maior ou menor diretividade ou normatividade para os usos de tempos e espaços na Educação Infantil.

Foram apresentados e discutidos autores que assumiam ações mais radicais nesses sentidos, como Russo (2008), que permite que as crianças entrem em um fluxo de escolhas próprias, abrindo espaço para a liberdade com menos cerceamento e sem intenções programáticas, mas lidando com "práticas de uso de objetos lúdicos" (p. 159), menos 
estruturados e especializados e mais transformáveis para que elas se divirtam e aprendam de modo inteligente (p. 159). E permitindo o acaso e a surpresa, que se tornam oportunidade, tanto para elas como para ele.

No caso dos ateliês freinetianos se distribuem espacialmente tarefas a serem desenvolvidas, muitas vezes, organizadas sob a forma de linguagens (artísticas, escritas e orais, matemáticas, corporais etc), e no caso das zonas circunscritas como são apresentadas por Nono (2011), o espaço é organizado pelas necessidades e interesses das crianças (o que fazem, como, do que gostam, que lugares preferem, o que lhes chama a atenção, momentos tranquilos e agitados), normalmente apenas contendo divisórias de 3 paredes baixas com uma entrada, para que as crianças tenham privacidade.

Ou ainda, o trabalho por projetos (Fernandes, Romaguera, 2015), em que o conceito de projeto é entendido como algo que se lança no tempo e no espaço, sem determinação prévia dos caminhos, tomando-se algo como ponto de partida e estabelecendo relações a partir da ideia de rizoma.

Tomando como base os documentos oficiais, bibliografia e exercícios práticos, o curso proporcionou questionamentos e provocações a fim de que os participantes e gestores se inquietassem e duvidassem de suas certezas, bem como repensassem o currículo em construção, abrindo espaço para criação.

Como tentativa de visualizar possíveis deslocamentos, um exercício pedido no começo do curso para os participantes foi que fotografassem os espaços e os usos dele pelas crianças, e que contassem como se dava a relação com o tempo. Ao final do curso, o exercício foi repetido, visando que aparecessem novas visões e escutas sobre o mesmo fato ou, no caso de persistirem, atribuir sentido para isso.

Durante as socializações, os participantes buscaram mostrar o que havia de deslocamento na reapropriação dos espaços e dos tempos, como passaram a ver e a escutar os movimentos das crianças que já existiam, mas que não haviam sido levados em conta inicialmente e algumas manutenções em razão de se necessitar de um amadurecimento interno para que algo novo pudesse acontecer.

$\mathrm{Na}$ sequência, foi pedido que fizessem uma representação de como estavam internamente, ou seja, que "fotografassem" seus espaços e tempos, para que, a partir disso, pudessem dar voz e escuta para seus próprios movimentos de inovação ou de manutenção. E, então, que os dois exercícios pudessem conversar, no sentido de se vejo e escuto-lá é porque vejo e escuto-aqui, em mim e o contrário também. 
A construção dos portfólios individuais ou coletivos foi outra oportunidade de, ao buscar na memória as lembranças e esquecimentos, dar historicidade para o percurso e utilizando-se de imagens, sensações, palavras que simbolizassem e dessem sentido para o experienciado. Ao lidarem com símbolos, construíram metáforas.

Grande parte dos participantes optou por construí-lo individualmente e poucos preferiram fazê-lo coletivamente, o que se mostrou um trabalho interessante, na medida em que os componentes do grupo precisaram compor em uma narrativa visual os sentidos que foram atribuídos por cada um, mas em vivências passíveis de serem socializadas.

Os suportes escolhidos variaram e em grande parte indicaram abertura e maleabilidade, em que os objetos e palavras escolhidos para compor com esse suporte eram visíveis, como no caso do guarda-sol, de móbile, de tecido, melancia aberta, vaso sanitário, fios. Em apenas um caso o suporte escolhido foi uma caixa, que indica abrigo, proteção, entretanto, a razão da caixa era ser aberta para se conhecer o que havia tanto dentro dela quanto na parte interna da tampa. Um participante usou um ponto de interrogação como representação de seu processo interno. Junto da dúvida - essencial para o pensamento -, apareceram muitos círculos (que indicam totalidade, ciclos) e espirais (que indicam movimento para fora ou para dentro, círculos concêntricos) que indicam fluxo e mudanças.

Logo, ao escolherem símbolos potentes para comporem uma narrativa em que conversam a forma e o conteúdo, também disseram de si e de seus momentos, assim como um tanto de si não pôde ser dito, visualizado, exteriorizado, pois que talvez não pudesse ser ou não se quisesse.

\section{Considerações finais}

Para se pensar a identidade da Educação Infantil a partir de suas especificidades precisa-se repensar o papel dos adultos e da formação dos profissionais que atuam com as crianças pequenas, de modo a buscar a construção de singularidades lá e cá, ou seja, em si e no espaço de trabalho.

Os cursos de formação continuada são uma oportunidade de provocar fazeres e pensares para e a partir da ação educativa atualizando e ajustando modos de ser, sentir, pensar e fazer. Supondo-se que vida e trabalho estão unidos, a mudança, as ressonâncias e os deslocamentos internos, bem como as repercussões e deslocamentos externos dos/as professores/as e monitores/as também caminham juntos é no movimento e nos riscos para a 
aprendizagem que se pode pensar e melhor realizar a ação educativa e de cuidado com as crianças pequenas.

Conhecer as marcas de processos de educação escolar e fora dela contribui para se conhecer as escolhas e orientações postas em prática e mantê-las ressignificadas ou inventar outros modos possíveis de se educar, que sustentam projetos e utopias.

Como escapar ou criar espaços de fuga? Apostando na deriva e na qualidade criativa dos tempos de Kairós e aión sobre a direção e orientação que o mapa indica e sobre o capitalístico tempo de chronos?

Para fazer diferente é preciso tomar referências teóricas e práticas de outros lugares. É fazer novas perguntas para deslocar-se e re-inventar-se e isso implica abrir-se para o risco das incertezas, do imprevisível, do desconhecido, em que se perde nosso suposto saber prévio, desafios a serem tomados em termos pedagógicos, emocionais e sensíveis, corporais, de pensamento reflexivo, de (auto)conhecimento. É assumir o tateio e o erro como forma generativa de experimentações e potência de experiências, inclusive, de nos colocarmos em vazios e labirintos.

A criação e a execução desse curso de formação partiram desses princípios e buscou o desconhecido, optou em alguns momentos estar à deriva, no vazio e alerta para não perder Kairós. Na avaliação do curso por parte dos participantes ficou apontado que a expectativa de alguns era por um curso de formação mais prescritivo inicialmente, porém ainda que buscando algo com alguma aplicabilidade prática e proveniente de modelos, alguns tentaram sair de suas cavernas e aproveitaram a suspensão, o respiro e a ausência de normatividade.

Como todo e qualquer trabalho interno, o conhecimento é algo que se constrói aos poucos e nem sempre se tem consciência das mudanças e deslocamentos, e nem sempre eles acontecerão no momento de finalização de um curso, mas continuarão repercutindo e ressoando até que possam ser percebidos e evocados.

O contato com a infância que nos habita e as relações com as crianças pequenas são a oportunidade, o momento, a situação de nos revermos e de repensarmos a instituição de acolhimento infantil com suas práticas e organização dos espaços-tempos, suas tentativas de capturas de sentidos e de corpos, suas tentativas de imposição de poder, porque é saber. Que isso ressoe e repercuta outras possibilidades de sermos e de nos fazermos. 


\section{REFERÊNCIAS}

BARBUY, Santiago. O espaço do encontro humano. São Paulo: Ece, 1980, 53 p.

CADERNO CURRICULAR TEMÁTICO EDUCAÇÃO BÁSICA: AÇÕES

EDUCACIONAIS EM MOVIMENTO. VOLUME I ESPAÇOS E TEMPOS NA

EDUCAÇÃO DAS CRIANÇAS. Prefeitura Municipal de Campinas, Secretaria Municipal de Educação, Departamento Pedagógico. Campinas, SP, 2014.

\section{DIRETRIZES CURRICULARES DA EDUCAÇÃO BÁSICA PARA A EDUCAÇÃO}

INFANTIL: um processo contínuo de reflexão e ação. Prefeitura Municipal de Campinas, Secretaria Municipal de Educação, Campinas/SP, 2013.

ELIAS, Norbert. Sobre o tempo. Rio de Janeiro: Zahar, 1988, 165 p.

FARIA, Ana Lúcia G. de. Vias não formais na educação infantil. In: PARK, Margareth B.; FERNANDES, Renata S.; CARNICEL, Amarildo. Palavras-chave em educação não formal. Holambra: Setembro, Campinas: CMU/UNICAMP, 2007. p. 291-292.

FERNANDES, Renata S.; ROMAGUERA, Alda. Experimentações, leituras, projetos. Americana: Adônis, 2015, 207 p.

FREINET, Célestin. Para uma escola do povo: guia prático para a organização material, técnica e pedagógica da escola popular. Lisboa: Presença, 1969.

GRUPO GINÁSTICO UNICAMP. Disponível em: http://www.ggu.com.br/ggu-apresentacao. Acesso em: 16 ago. 2017.

HANNA, Thomas. Corpos em revolta: a evolução-revolução do homem do século XX em direção à cultura somática do século XXI. Rio de Janeiro: Mundo Musical, 1972.

KENSKI, V. M. Memória e prática docente. In: BRANDÃO, C. R. (Org.). As faces da memória. Campinas: Centro de Memória - Unicamp, [s/d]. p. 101- 114.

LARROSA, Jorge. O enigma da infância. In: Pedagogia profana: danças, piruetas e mascaradas. Belo Horizonte: Autêntica, 2010, p. 183-198.

LARROSA, Jorge. Tremores - escritos sobre a experiência. Belo Horizonte: Autêntica, 2015, $175 \mathrm{p}$.

MATURANA, Humberto e de REZEPKA, Sima Nisis. Formación humana y capacitación. Santiago: Dolmen Ediciones S. A., 1997.

NARANJO, Cláudio. Mudar a educação para mudar o mundo: o desafio do milênio. Brasília: Verbena, 2015, 352 p.

NONO, Maévi A. Organização do tempo e do espaço na Educação infantil - pesquisas e práticas. In: Caderno de formação: formação de professores educação infantil: princípios e 
fundamentos/Universidade Estadual Paulista. Pró-Reitoria de Graduação, Universidade Virtual do Estado de São Paulo. São Paulo: Cultura Acadêmica, 2011, p. 95-106.

ROCHA, Eloisa Acires Candal. A função social das instituições de educação infantil. Zero-aSeis, Florianópolis, v. 5, n. 7, p. 13-23, jan. 2003. Disponível em:

〈https://periodicos.ufsc.br/index.php/zeroseis/article/view/799/9390>. Acesso em: 16 ago. 2017.

RUSSO, Danilo. De como ser professor sem dar aulas na escola da infância (III). Revista Eletrônica de Educação. São Carlos, SP: UFSCar, v.2, no. 2, p. 149-174, nov. 2008. Disponível em 〈http://www.reveduc.ufscar.br>. Acesso em: 16 ago. 2017.

VELARDI, Marília. Metodologia de ensino em educação física: contribuições de Vygotsky para as reflexões sobre um modelo pedagógico. 1997. 200f. Dissertação (Mestrado em Educação Física) - Faculdade de Educação Física, Universidade Estadual de Campinas, Campinas.

Agradecimento especial a Simone Pinto da Silva por todas as ajudas e colaborações que deram sustentação a escrita deste artigo.

\section{SOBRE AS AUTORAS}

\section{Renata Sieiro Fernandes}

Doutora e pós-doutora em Educação pela Universidade Estadual de Campinas (UNICAMP). Docente do programa de Mestrado em Educação do Centro Universitário Salesiano de São Paulo (UNISAL), unidade Americana - SP. Membro do Grupo de Pesquisa CAIPE Conhecimento e Análise das Intervenções na Práxis Educativa Sociocomunitária do UNISAL e do grupo Educação, Linguagem e Práticas Culturais - PHALA/UNICAMP. E-mail: rsieirof@hotmail.com e renata.fernandes@unisal.br

\section{Andrea Desidério da Silva}

Doutoranda em Educação Física, pela Universidade Estadual de Campinas (UNICAMP) - SP. Professora da Escola do Sítio, Campinas-SP. Membro do Grupo de Pesquisa em Ginástica, do Grupo de Estudos e Pesquisas Pedagógicas em Ginástica e do Grupo de Pesquisa em Ginástica do LAPEGI/FCA/UNICAMP. E-mail: andreaggu@ yahoo.com.br 